\title{
Subjective assessments of comorbidity correlate with quality of life health outcomes: Initial validation of a comorbidity assessment instrument
}

\author{
Elizabeth A Bayliss*1,2, Jennifer L Ellis ${ }^{1}$ and John F Steiner ${ }^{1,3}$
}

Address: ${ }^{1}$ Kaiser Permanente, PO Box 378066, 80237-8066 Denver, CO, USA, ${ }^{2}$ Department of Family Medicine, University of Colorado Health Sciences Center, Denver, CO, USA and ${ }^{3}$ Colorado Health Outcomes Program, University of Colorado Health Sciences Center, Denver, CO, USA

Email: Elizabeth A Bayliss* - Elizabeth.Bayliss@kp.org; Jennifer L Ellis - Jenn.L.Ellis@kp.org; John F Steiner - John.Steiner@uchsc.edu

* Corresponding author

Published: 0 I September 2005

Health and Quality of Life Outcomes 2005, 3:5। doi:10.1 I86/1477-7525-3-

51

This article is available from: http://www.hqlo.com/content/3/I/5।

(c) 2005 Bayliss et al; licensee BioMed Central Ltd.

This is an Open Access article distributed under the terms of the Creative Commons Attribution License (http://creativecommons.org/licenses/by/2.0), which permits unrestricted use, distribution, and reproduction in any medium, provided the original work is properly cited.

\begin{abstract}
Background: Interventions to improve care for persons with chronic medical conditions often use quality of life $(\mathrm{QOL})$ outcomes. These outcomes may be affected by coexisting (comorbid) chronic conditions as well as the index condition of interest. A subjective measure of comorbidity that incorporates an assessment of disease severity may be particularly useful for assessing comorbidity for these investigations.
\end{abstract}

Methods: A survey including a list of 25 common chronic conditions was administered to a population of HMO members age 65 or older. Disease burden (comorbidity) was defined as the number of self-identified comorbid conditions weighted by the degree (from I to 5 ) to which each interfered with their daily activities. We calculated sensitivities and specificities relative to chart review for each condition. We correlated self-reported disease burden, relative to two other wellknown comorbidity measures (the Charlson Comorbidity Index and the RxRisk score) and chart review, with our primary and secondary QOL outcomes of interest: general health status, physical functioning, depression screen and self-efficacy.

Results: 156 respondents reported an average of 5.9 chronic conditions. Median sensitivity and specificity relative to chart review were $75 \%$ and $92 \%$ respectively. QOL outcomes correlated most strongly with disease burden, followed by number of conditions by chart review, the Charlson Comorbidity Index and the RxRisk score.

Conclusion: Self-report appears to provide a reasonable estimate of comorbidity. For certain QOL assessments, self-reported disease burden may provide a more accurate estimate of comorbidity than existing measures that use different methodologies, and that were originally validated against other outcomes. Investigators adjusting for comorbidity in studies using QOL outcomes may wish to consider using subjective comorbidity measures that incorporate disease severity. 


\section{Background}

The goal of caring for persons with chronic medical conditions is frequently to maximize quality of life (QOL) rather than to 'cure' illness. Therefore interventions to improve processes of care for this population often assess QOL outcomes such as physical functioning, overall health status, and emotional well being. These outcomes are, by definition, subjective. The values assigned to these outcomes are most meaningful to the patients themselves. However, these subjective outcomes have been shown to correlate with mortality, health care utilization, job loss, and many other more 'quantifiable' outcomes [1-3].

The outcomes of a chronic condition may be affected by coexisting (comorbid) chronic conditions as well as the index condition of interest and analyses must adjust for this effect of comorbidity. Multiple instruments have been developed and validated to quantify comorbidity for purposes of statistical adjustment and clinical decision making. The majority of these use medical record review or administrative data as sources of information; observation during clinical encounters and self report have also been used for this purpose. These instruments have primarily been validated against 'objective' health outcomes such as mortality, length of stay, and cost of care [4-13]. We are aware of two such instruments that have been validated against QOL outcomes [5,14]. In addition, many of these instruments were designed for use in hospitalized patients or populations characterized by specific illnesses.

Self-reported information about comorbidity and the burden it imposes can provide information about the concurrent impact of multiple disease states on QOL outcomes. Self-reported comorbidity information is also efficient in studies in which other information, such as QOL outcomes, is collected by survey. Instruments designed to assess comorbidity by self-report have reported significant correlations between comorbidity score and utilization, QOL, mortality and hospitalization [15-20].

It is important to incorporate assessment of disease severity into comorbidity measurement [6]. Some self-report instruments incorporate various weighting systems for this purpose and two of these have been validated in hospitalized populations $[15,18]$. We have developed a selfreport instrument that incorporates disease severity by quantifying the respondent's subjective 'disease burden' which we define as the number of self-identified comorbid conditions weighted by the degree to which each condition limits daily activity. We hypothesized that a subjective measure of comorbidity such as this may be more strongly correlated with QOL outcomes than measures of comorbidity previously validated against other, more objective, health outcomes.
Our goals in this investigation were to validate this newlydeveloped instrument against a presumed 'gold standard' of chart review, and to conduct an initial comparison of this instrument with other well known measures of comorbidity (chart review of number of conditions, the Charlson Comorbidity Index and the RxRisk score) by correlating these measures with selected QOL outcomes.

\section{Methods \\ Study setting and sample selection}

The study setting was a Health Maintenance Organization (HMO) in the United States that provides primary, specialty and hospital care for persons of all ages. Due to the use of an electronic medical record, both primary and specialty providers can enter diagnoses and assessments into a single patient record. Participants were selected from a stratified random sample of HMO members age 65 or older with $0(8 \%), 1(10 \%), 2(12 \%)$, or 3 or more $(69 \%)$ chronic medical conditions. We sampled this age group based on the high prevalence of comorbid conditions in older adults [21]. The stratification was performed with a modified version of the RxRisk comorbidity assessment instrument that uses administrative pharmacy data to determine an estimated disease count [4]. As one of the goals of our investigation was to assess issues of importance to persons with multiple comorbidities, we oversampled members with a greater number of chronic conditions. Due to the pilot nature of the study, we used consecutive random sampling in increments of single mailings until we had sufficient sample size to evaluate the instrument. We calculated that we would need a sample size of 139 for an expected proportion (sensitivity and specificity) of 0.90 to have a $95 \%$ confidence interval with a total width of 0.10 .

\section{Instrument development}

We searched the literature to determine the health conditions most frequently assessed in measuring comorbidity $[4,5,7,17,22-26]$. From this we assembled a list of 25 common chronic conditions and coupled it with a scale that asked respondents to report for each condition a) whether they had the condition, and b) if so whether it interfered with their daily activities "not at all' (a weight of 1) to "a lot" (a weight of 5). These responses then provided a measure of 'disease burden' (comorbidity) that resulted from weighting each reported condition by the degree of limitation. These conditions are listed in Table 2. Depression is absent from the list of morbidities as it was assessed as a separate outcome measure. As there is a known correlation between comorbidity and physical dimensions of QOL, we chose overall health status and physical functioning as our primary outcomes of interest [14]. We also investigated depression and self-efficacy as secondary outcomes important in caring for persons with multiple morbidities. 
Table 2: Sensitivity and Specificity of Self-Report Relative to Chart Review $\left(N=15 I^{\prime}\right)$

\begin{tabular}{|c|c|c|c|c|c|}
\hline \multirow[b]{2}{*}{ Medical condition'2 } & \multirow[b]{2}{*}{$\begin{array}{l}\text { Mean Self-Report } \\
\text { Disease Burden }\end{array}$} & \multicolumn{2}{|c|}{ Prevalence } & \multirow[b]{2}{*}{$\begin{array}{c}\text { Sensitivity } \\
(\%)\end{array}$} & \multirow[b]{2}{*}{$\begin{array}{c}\text { Specificity } \\
(\%)\end{array}$} \\
\hline & & $\begin{array}{c}\text { Self-Report n } \\
(\%)\end{array}$ & $\begin{array}{c}\text { Chart Review n } \\
(\%)\end{array}$ & & \\
\hline Angina/coronary artery disease & 2.2 & $19(12)$ & $39(25)$ & 41 & 97 \\
\hline Asthma & 2.7 & $20(13)$ & $12(8)$ & 100 & 94 \\
\hline Back pain & 3.0 & $61(39)$ & $37(24)$ & 92 & 77 \\
\hline Bronchitis, chronic/COPD & 3.1 & $20(13)$ & $20(13)$ & 70 & 96 \\
\hline Cancer (within the past 5 yrs) & 1.7 & I I (7) & $20(13)$ & 55 & 100 \\
\hline Cholesterol, elevated & 1.6 & $81(52)$ & $78(50)$ & 89 & 85 \\
\hline Colon problem (e.g., diverticulitis, irritable bowel) & 2.8 & $21(14)$ & $12(8)$ & 75 & 92 \\
\hline Congestive heart failure & 2.5 & $23(15)$ & $23(15)$ & 74 & 96 \\
\hline Diabetes & 2.2 & $31(20)$ & $32(21)$ & 88 & 98 \\
\hline Hard of hearing & 2.6 & $75(48)$ & $32(21)$ & 81 & 61 \\
\hline Hypertension & 1.8 & $95(6 I)$ & $103(66)$ & 84 & 83 \\
\hline Kidney disease & 2.0 & $6(4)$ & $17(11)$ & 35 & 100 \\
\hline Nerve condition & 3.4 & $9(6)$ & $15(10)$ & 47 & 99 \\
\hline Osteoarthritis & 2.8 & 72 (46) & 69 (44) & 73 & 75 \\
\hline Osteoporosis & 2.1 & $30(19)$ & $22(14)$ & 86 & 92 \\
\hline Overweight & 2.4 & $70(45)$ & $28(18)$ & 96 & 66 \\
\hline Poor circulation (e.g., peripheral vascular disease) & 3.0 & $44(28)$ & $14(9)$ & 93 & 78 \\
\hline Rheumatic disease, other & 3.2 & $5(3)$ & $4(3)$ & 75 & 99 \\
\hline Rheumatoid arthritis & 3.2 & $25(16)$ & $4(3)$ & 75 & 86 \\
\hline Stomach problem (e.g., gastritis, peptic disease) & 2.3 & $46(30)$ & $40(26)$ & 75 & 86 \\
\hline Stroke & 2.4 & $16(10)$ & $20(13)$ & 60 & 97 \\
\hline Thyroid disorder & 1.5 & $39(25)$ & $41(26)$ & 90 & 98 \\
\hline Vision problem & 2.3 & $98(63)$ & $109(70)$ & 78 & 72 \\
\hline
\end{tabular}

I Total $\mathrm{N}=156, \mathrm{I} 5 \mathrm{I}$ participants reported I or more conditions.

2 For most conditions, an example or two were provided to illustrate the diagnostic category. For example, 'other rheumatic disease" was presented as "rheumatic disease such as fibromyalgia or lupus"; and "nerve condition" was presented as "nerve condition such as Parkinson's disease or multiple sclerosis."

\section{Survey administration}

We pre-tested the instrument for clarity and ease of completion with volunteers who were age 65 or older and had more than one chronic medical condition. Pre-testing was conducted in one-on-one interviews in which the volunteer completed the survey and then provided detailed feedback to the interviewer on the content and comprehension of the measure. Any recommended changes were incorporated into the subsequent version of the instrument. It was then mailed to respondents as a component of another pilot survey that assessed potential barriers to the medical self-care process. The complete questionnaire included validated questions that assessed physical functioning and general health status, a depression screen, and an adapted and concurrently validated assessment of general self-efficacy. We used the physical functioning measure and the general health status single question from the Short-Form $36^{\circledR}$, the depression screen from the Behavioral Risk Factor Surveillance System, and a concurrently validated adaptation of the general self-efficacy scale (our coefficient alpha =0.76) [1,27-29]. We used these assessments as our primary and secondary QOL outcomes of interest for the current investigation. The investigation was approved by the Institutional Review Board of the participating HMO and informed consent was obtained from all participants.

\section{Comparison with chart review}

We compared each participant's responses with diagnoses listed in their electronic medical record. We reviewed assessments from all outpatient encounters over the two years preceding the survey and accepted at least two chartdocumented assessments of a chronic condition as an active diagnosis. Requiring two rather than one chart diagnosis may reduce the sensitivity of self-report [30]. However, we based our decision on the assumption that a recurrence of a chronic diagnosis would reasonably have been communicated to the patient, and therefore he or she might be expected to list that diagnosis in their response to our survey. Either two recorded outpatient diagnoses or one inpatient diagnosis have been suggested as a reasonable standard for a confirmed diagnosis [31]. In our chart review, we also counted previously documented chronic conditions that were likely to persist (e.g. 
hearing loss). We did not count diagnoses of chronic problems that had been surgically corrected and required no further management (e.g. cataract surgery).

\section{Comparison with other measures of comorbidity}

In addition to calculating comorbidity with our instrument, for each respondent we quantified level of comorbidity using two other validated comorbidity measurement tools. These two methods were the RxRisk score and the Charlson comorbidity index [4,7]. We chose these based on both their common use and the contrast they provided in methodologies since they use different methods of data collection and have been validated against different outcomes. The RxRisk score is a measure of comorbidity that incorporates age, gender, health insurance benefit status and an RxRisk category based on diagnoses derived from administrative pharmacy data. It was originally developed and validated to identify chronic conditions and to predict cost of health care, and subsequently revised to assess disease burden in certain populations $[4,32]$. We used administrative pharmacy data to apply the RxRisk tool to our study population. The Charlson comorbidity index is a widely used comorbidity measure that was originally developed to predict one-year mortality following hospitalization. The score is based on chart review for specified diagnostic criteria. It has been subsequently adapted and revalidated to assess longer term mortality, disability, hospital readmission and length of stay and has been revised into formats that utilize either ICD-9 diagnosis codes or questionnaire [68,25 . We calculated the Charlson comorbidity score using chart review.

\section{Statistical methods}

We calculated sensitivity and specificity for each condition using the chart report as the 'gold standard.' We also calculated sensitivity and specificity for each participant to indicate the percent of positive and negative conditions on which the respondent and chart agree relative to the total positive or negative conditions in the chart. Thus specificity and sensitivity by condition reflect respondents' overall tendency to accurately report a given condition relative to chart report, and sensitivity and specificity by participant reflect respondents' overall tendency to accurately report on all of their conditions in comparison to the gold standard of chart review. (Note that sensitivity and specificity analyses used self-reported presence or absence of conditions for comparison rather than the weighted disease burden score.) In order to further compare selfreported disease burden with our 'gold standard' of chart review, for each condition we entered self-reported disease burden followed by chart report of that condition into limited logistic regression models to assess the relative contributions of each of these independent variables
Table I: Characteristics of study population $(N=156)$

\begin{tabular}{|c|c|}
\hline Characteristic & Number (\%) \\
\hline Age (mean, range) & $75.0,67-94$ \\
\hline \multicolumn{2}{|l|}{ Gender } \\
\hline Male & $75(48.1)$ \\
\hline Female & $77(49.4)$ \\
\hline Missing, chose not to answer & $4(2.6)$ \\
\hline \multicolumn{2}{|l|}{ Marital status } \\
\hline Married & $101(64.7)$ \\
\hline Widowed & $33(21.2)$ \\
\hline Divorced/separated & $18(11.5)$ \\
\hline Missing, chose not to answer & $4(2.6)$ \\
\hline \multicolumn{2}{|l|}{ Education level } \\
\hline Did not graduate high school & $16(10.3)$ \\
\hline High school graduate & $42(26.9)$ \\
\hline Some college & $42(26.9)$ \\
\hline College graduate & $20(12.8)$ \\
\hline Post-college & $31(19.9)$ \\
\hline Missing, chose not to answer & $5(3.2)$ \\
\hline \multicolumn{2}{|l|}{ Household income (mean category) } \\
\hline Less than $\$ 15,000$ & $22(14.1)$ \\
\hline$\$ 15,000-30,000$ & $38(24.4)$ \\
\hline$\$ 30,000-45,000$ & $29(18.6)$ \\
\hline$\$ 45,000-60,000$ & $20(12.8)$ \\
\hline$\$ 60,000-75,000$ & $12(7.7)$ \\
\hline$\$ 75,000-90,000$ & $\mathrm{I}(0.6)$ \\
\hline More than $\$ 90,000$ & $5(3.2)$ \\
\hline Missing, chose not to answer, don't know & $29(18.6)$ \\
\hline \multicolumn{2}{|l|}{ Race } \\
\hline Caucasian & $142(9 \mid .0)$ \\
\hline African-American & $\mathrm{I}(0.6)$ \\
\hline Other & $7(4.5)$ \\
\hline Missing, chose not to answer & $6(3.8)$ \\
\hline \multicolumn{2}{|l|}{ Hispanic ethnicity } \\
\hline Yes & $5(3.2)$ \\
\hline No & $13 \mid(84.0)$ \\
\hline Missing, chose not to answer & $20(12.8)$ \\
\hline \multicolumn{2}{|l|}{ Health status } \\
\hline Excellent & $6(3.9)$ \\
\hline Very Good & $43(27.6)$ \\
\hline Good & $67(43.0)$ \\
\hline Fair & $30(19.2)$ \\
\hline Poor & $4(2.6)$ \\
\hline Missing & $6(3.9)$ \\
\hline \multicolumn{2}{|l|}{ Level of Comorbidity (mean, range of each) } \\
\hline Number of Self-Reported Conditions & $5.9,0-16$ \\
\hline Self-Reported Disease Burden* & $|3.9,0-5|$ \\
\hline
\end{tabular}

*Total score of limitations due to conditions (Sum of weights from I to 5 for each condition present).

to the predictive accuracy of the model for each of our outcome measures [33].

We calculated Spearman correlations between disease burden from the new instrument, disease count by chart review, the Charlson index and the RxRisk score, with our QOL outcomes of interest: measures of overall health sta- 
Table 3: Correlations Between Measures of Comorbidity and QOL Outcomes $\left(N=156^{2}\right)$

\begin{tabular}{|c|c|c|c|c|c|}
\hline & $\begin{array}{l}\text { Self reported } \\
\text { disease burden! }\end{array}$ & $\begin{array}{l}\text { Chart review number } \\
\text { of conditions }\end{array}$ & $\begin{array}{l}\text { Self reported number } \\
\text { of conditions }{ }^{3}\end{array}$ & $\begin{array}{l}\text { Charlson comorbidity } \\
\text { score [7] }\end{array}$ & Rx-risk score [4] \\
\hline Overall health status* $(n=150)$ & $0.60 p<0.001$ & $0.56 p<0.001$ & $0.477 p<0.001$ & $0.48 p<0.001$ & $0.17 P=0.037$ \\
\hline Physical functioning* $(n=137)$ & $-0.63 p<0.001$ & $-0.52 p<0.001$ & $-0.482 p<0.001$ & $-0.41 p<0.001$ & $-0.18 p=0.035$ \\
\hline Depression screen* $(n=153)$ & $-0.29 p<0.001$ & $-0.25 p=0.002$ & $-0.240 p=0.003$ & $-0.12 p=0.140$ & $-0.05 p=0.559$ \\
\hline Self-efficacy* $(n=145)$ & $-0.32 p<0.001$ & $-0.22 p=0.008$ & $-0.305 p<0.001$ & $-0.14 p=0.096$ & $0.10 p=0.234$ \\
\hline
\end{tabular}

* For health status, a higher score implies worse perceived health; for other outcomes, a higher number implies a better functioning, less depression or greater self-efficacy.

I Total score of degree of limitation due to each positive condition ( $I=$ not at all to $5=$ a lot $)$.

2 Due to missing scale scores, total $\mathrm{n}$ ranged from 137 (physical activity) to 154 (social activity).

${ }^{3}$ Number of conditions from the list that were positively reported by the respondent.

tus, physical functioning, positive depression screen, and level of self-efficacy.

\section{Results}

After two consecutive single mailings, 157 individuals completed the survey. The response rate of $28 \%$ was obtained without the use of strategies typically employed to increased response, such as multiple mailings or more active follow-up. Characteristics of respondents are noted in Table 1. Mean age was 75, health status ranged from excellent to poor and respondents reported an average of 5.9 chronic conditions. Respondents did not differ from non-respondents with regard to age, gender, number of chronic conditions (as estimated by the initial screen with the RxRisk instrument), or duration of $\mathrm{HMO}$ membership.

One hundred fifty-one respondents reported at least one of the conditions and 6 reported none. In analyses by condition, median sensitivity of patient report of a condition relative to a 'gold standard' of chart review was $75 \%$ (range $35 \%$ to $100 \%$ ) and median specificity was $92 \%$ (range $61 \%$ to $100 \%$ ). In analyses by respondent, sensitivities (agreement on number of conditions positive relative to chart review) ranged from $14 \%(\mathrm{n}=1)$ to $100 \%(\mathrm{n}=$ 53 ); the median was $83 \%$. Sensitivities were not calculated for the ten respondents who did not agree with the chart on any conditions, including those who agreed with their medical record that they had none of the conditions $(\mathrm{n}=2)$. Specificities by respondent ranged from $59 \%(\mathrm{n}=$ 1) to $100 \%(\mathrm{n}=34)$; the median was $91 \%$. Sensitivity and specificity of self-report of each condition relative to chart review are reported in Table 2. (Not included on the table are results for 2 of the original 25 conditions: liver disease and alcoholism. Two respondents and one separate chart reported alcohol abuse, and no respondents or charts reported liver disease.)

In order to assess the relative contributions of self reported diseases and disease count by chart review to the outcomes of general health status and physical functioning, we entered these two variables into limited logistic regression models. In these models containing only these two variables, the predictive accuracy of the model (as measured by the c-statistic) was not significantly different using each of the two variables, implying comparable contributions of either measure. C-statistics for overall health status ranged from 0.521 ("other rheumatic disease) to 0.669 ("osteoarthritis"); and for physical functioning ranged from 0.515 ("other rheumatic disease") to 0.679 ("overweight").

QOL outcomes of interest correlated most strongly with self-reported disease burden, followed by number of conditions by chart review, self-reported number of conditions, the Charlson index score and the RxRisk score. Although all measures of comorbidity except the RxRisk score showed comparable $p$ values $(\mathrm{p}<=0.001)$ for the outcomes of health status and physical functioning, the correlations for disease burden were significantly stronger than those for self-reported number of conditions or Charson comorbidity score for these outcomes. Table 3 lists these correlations for our primary outcomes of interest - overall health status and physical functioning - and our secondary outcomes of positive screen for depression and self-efficacy.

\section{Discussion}

It is important to incorporate assessment of comorbidity into studies involving QOL outcomes for persons with chronic medical conditions, as coexisting conditions may substantially affect outcomes of interest such as physical functioning, overall health status, depression and self-efficacy. In our study population, patients with multiple chronic medical conditions accurately reported a majority of common comorbid conditions relative to chart review. In addition, they were aware of most of their own diagnoses. Furthermore, self-reported disease burden correlated well with QOL outcomes, and correlated more strongly than did the two other measures of comorbidity 
that we used for comparison. This is consistent with our hypothesis that, for investigations using QOL outcomes, it is most appropriate to adjust for comorbidity using a subjective measure of comorbidity.

Previous investigations that have compared self-report with administrative data reported $59-79 \%, 72-73 \%$, and $78-83 \%$ agreement on diagnoses of hypercholesterolemia, diabetes, and hypertension respectively; and 56\% and $69 \%$ agreement on stroke and myocardial infarction $[30,34]$. In our investigation we expanded the number of conditions for comparison to 23 and additionally assessed respondents' tendencies to accurately report all of their own conditions. Certain diagnoses were reported with high levels of sensitivity and specificity, while others were not.

A sensitivity greater than specificity may be due to either 'over-reporting' by participants or 'under-reporting' in the chart. Examples from our list included asthma, back pain, overweight and hard-of-hearing. We suspect that, for the first case, some participants reported COPD as asthma. For the remaining cases, we suspect that the conditions were under-reported in the chart - either because they had not been brought to medical attention or because they had not been assessed as isolated problems in the context of medical visits during the period covered by the chart review.

Sensitivity was substantially less than specificity for angina, nerve conditions, cancer and kidney disease. Although there may be a tendency to under-report chronic conditions, and respondents are more likely to report conditions with more severe symptoms $[17,35]$; we rereviewed charts of persons with these diagnoses to see if we could determine the cause of the discrepancies. From these repeat chart reviews, we concluded that these discrepancies were due to wording based more on symptoms than diagnosis (angina), under-reporting of conditions with stable or few symptoms (renal and neurological), and possible perceptions of cure or remission after acute treatment (cancer). In addition we analyzed the demographic and health characteristics (from Table 1) of respondents for each of these four conditions to see if any demographic or disease characteristics were likely to predict a low agreement with chart review and found no patterns.

In our assessments of sensitivity and specificity, we assumed that the presence of a diagnosis in the chart was a 'gold standard' - an assumption that may not be entirely accurate. We suspect that diagnoses for which there are obvious medical treatments - especially medications - are more likely to be recorded in the chart. Chart diagnoses may be less accurate for conditions for which a person is less likely to seek (or for which a provider is less likely to offer) specifically biomedical solutions.

We found a high correlation between our measure of disease burden and our QOL outcomes of interest, as compared to lower correlations between two other comorbidity indices and these same outcomes. However, the correlations between the other comorbidity indices and health status and physical functioning were also significant and have been noted previously [36]. The correlations between the Charlson and RxRisk scores and our secondary outcomes of interest (depression screen and self-efficacy) were not significant. Based on the pattern of these associations, we suggest that assessment of comorbidity is a function of the outcome of interest, the population studied, and the different (subjective versus objective) aspects of comorbidity measured by each instrument. The effect of comorbidities on QOL outcomes may be most accurately assessed when subjective measures are used to adjust for comorbidity. In contrast, for situations in which mortality, for example, is the outcome of interest, comorbidity should be assessed using instruments that have been developed for that purpose. These suggestions are consistent with the notion that 'complete' measurement of all health states requires both selfreported and objectively reported measures [37].

It is certainly possible that one comorbidity measure may work for many situations. Other self-report instruments have been shown to predict mortality and hospitalization in addition to QOL $[15,16,18]$. We are also aware of at least two investigations in which comorbidity measured by chart review correlated with QOL outcomes $[5,14]$. The two instruments with which we compared our own instrument use different methodologies and were originally developed to assess comorbidity in studies investigating the objective outcomes of mortality and cost of care respectively $[4,7]$. The Charlson index has been subsequently validated against length of stay, post operative complications, discharge to nursing home, disability, hospital readmission and hospital charges [6,8,38-40]. The RxRisk score has subsequently been adapted and validated against administrative data on diagnoses and disease burden in certain populations [4,32]. Our investigation adds to the growing body of knowledge on measuring comorbidity by highlighting the different results that may be obtained when using different methodologies to adjust for comorbidity in studies assessing QOL outcomes.

We did not incorporate additional measures of comorbidity, such as those that use administrative data into our analysis $[8,12,13]$. Previous comparative studies suggest that chart-review-based measures may be slightly more accurate than administrative data-based comorbidity 
measures in predicting objective outcomes such as mortality and length of hospital stay $[6,38,41]$. Further investigation is necessary to assess association of comorbidity measured by administrative data with QOL outcomes.

As with any initial validation effort, the generalizability of our conclusions is limited by the characteristics of the population studied - a relatively small HMO population aged 65 years or older. It is possible that this population is relatively 'well-educated' regarding the number and type of their medical conditions. If so, some of the sensitivities we report may be at the upper end of the spectrum that may be anticipated from self-report. In addition, we terminated the sampling process when we attained a sample size sufficient to test our primary hypothesis, without maximizing response rate. Thus, the findings in this sample may not represent the associations of a broader population. Although respondents did not differ significantly from non-respondents on RxRisk comorbidity score, more motivated or knowledgeable participants may have been more likely to respond promptly to our survey. Correlations and sensitivities could be lower when examined in a less motivated population or those with a lower knowledge base. Specifically, self-report may be less reliable in the geriatric sub-population that may suffer from cognitive impairment. Additional validation studies will be required in order to assess the usefulness of this instrument in other populations and for different QOL and other outcomes. We anticipate that these changes will strengthen our results for sensitivity in comparison to chart review and that they will not change the overall correlations with our outcomes of interest.

Disease burden (as we defined it) may in itself constitute a substantial portion of any patient's assessment of health status and physical functioning. Our incorporation of perceived limitation into a disease count may be similar to other investigations that have coupled a simple disease count with a health status measure such as the SF- $36{ }^{\circledast}$ and found that doing so strengthened the relationship between comorbidity and utilization and mortality $[16,19]$. However, models that attempt to explain the relationship between symptom burden, overall quality of life and physical functioning note that these outcomes are also affected by environmental characteristics, individual personality, expectations, values, and social and psychological supports $[42,43]$. What we refer to as disease burden explains part, but not all, of our QOL outcomes as is illustrated by the values of our c-statistics. To the extent that investigations that use QOL outcomes concentrate on participants with one index condition and need to adjust for comorbidities, a subjective measure of disease burden using self-report may be an accurate way to account for the effect of other coexisting conditions with regard to that outcome.
Finally, depression is both an important potential comorbidity for anyone with chronic illness as well as an equally important component of the QOL outcome of emotional well being. We chose to treat it as the latter. As depression severity independently contributes to general QOL over and above other coexisting chronic illness, we suspect that including depression on our list of conditions would have increased the strength of correlations between selfreported disease burden and general health status [44,45].

\section{Conclusion}

Assessing comorbidity is relevant to investigations of populations with multiple medical conditions and should be incorporated into the associated analyses. Not only is selfreport likely to give a reasonable estimate of comorbidity, for investigations using QOL outcomes, self-reported disease burden (or other subjective assessments of comorbidity) may provide a more accurate comorbidity adjustment than measures that have been validated against other outcomes. If this finding is confirmed by additional investigation, subjective measures of comorbidity that incorporate disease severity should be added to QOL assessments for populations with high rates of comorbidity.

\section{Authors' contributions}

EB conceived the study, designed the comorbidity instrument, supervised survey administration and drafted the manuscript. JE participated in the design of the study, performed the statistical analysis, and participated in the data review and manuscript preparation. IS consulted on all phases of the study design, data review and analysis, and participated in the manuscript preparation.

\section{Acknowledgements}

This project was funded by an internal research grant from Kaiser Permanente, Colorado.

Portions of this material were previously presented in poster format at the annual HMO Research Network Conference, Santa Fe, NM. April 2004.

\section{References}

I. Ware JE: SF-36(R) Health Survey Update. 2005.

2. Lawrence WF, Fryback DG, Margin PA, Klein R, Klein BEK: Health status and hypertension: A population-based study. J Clin Epidemiol 1996, 49:1239-1245.

3. Wagner EH, LaCroix AZ, Grothaus LC, Hecht JA: Responsiveness of health status measures to change in older adults. J Am Geriatr Soc 1993, 41:241-248.

4. Fishman PA, Goodman MJ, Hornbrook MC, Meenan RT, Bachman DJ, O'Keefe Rosetti MC: Risk adjustment using automated ambulatory pharmacy data. TheRxRisk model. Med Care 2003, 41:84-99.

5. Greenfield S, Apolone G, McNeil BJ, Cleary PD: The importance of co-existent disease in the occurrence of postoperative complications and one-year recovery in patients undergoing total hip replacement. Comorbidity and outcomes after hip replacement. Med Care 1993, 3 I:|4|-|54.

6. de Groot V, Beckerman H, Lankhorst GJ, Bouter LM: How to measure comorbidity: a critical review of available methods. J Clin Epidemiol 2003, 56:221-229. 
7. Charlson ME, Pompei P, Ales KL, MacKenzie CR: A new method of classifying prognostic comorbidity in longitudinal studies: development and validation. J Chron Dis 1987, 40:373-383.

8. Deyo RA, Cherkin DC, Ciol MA: Adapting a clinical comorbidity index for use with ICD-9 administrative databases. J Clin Epidemiol 1992, 45:613-619.

9. Katz JN, Chang LC, Sangha O, Fossel AH, Bates DW: Can comorbidity be measured by questionnaire rather than medical record review? Med Care 1996, 34:73-84.

10. Linn BS, Linn MW, Lee G: Cumulative illness rating scale. J Am Geriatr Soc 1968, 16:622-626.

II. Kaplan MH, Feinstein AR: The importance of classifying initial co-morbidity in evaluating the outcome of diabetes mellitus. J Chron Dis 1973, 27:387-404.

12. Starfield B, Weiner J, Mumford L, Steinwachs D: Ambulatory care groups: a categorization of diagnoses for research and management. Health Serv Res 1991, 26:53-74.

13. Elixhauser AE, Steiner C, Harris R, Coffey RM: Comorbidity measures for use with administrative data. Med Care 1998, 36:8-27.

14. Fortin M, Lapointe L, Hudon C, Vanasse A, Ntetu AL, Maltais D: Multimorbidity and quality of life in primary care: a systematic review. Health and Quality of Life Outcomes 2004, 2:5I.

15. Sangha O, Stucki G, Liang MH, Fossel AH, Katz JN: The self-administered comorbidity questionnaire: a new method to assess comorbidity for clinical and health services research. Arthritis Rheum 2003, 49: I56-163.

16. Fan VS, Au D, Heagerty P, Deyo RA, McDonell MB, Finn SD: Validation of case-mix measures derived from self-reports of diagnoses and health. I Clin Epidemiol 2002, 55:37I-380.

17. Klabunde CN, Reeve BB, Harlan LC, Davis WW, Potosky AL: Do patients consistently report comorbid conditions over time? Results from the prostate cancer outcomes study. Med Care 2005, 43:39I-400.

18. Chaudhry S, Jin L, Meltzer D: Use of a self-report-generated Charlson Comorbidity Index for predicting mortality. Med Care 2005, 43:607-6I5.

19. Hornbrook MC, Goodman MJ: Chronic disease, functional health status, and demographics: a multi-dimensional approach to risk adjustment. Health Services Research 1996, 3I:283-307.

20. Selim AJ, Fincke BG, Ren XS, Lee A, Rogers WH, Miller DR, Skinner KM, Linzer R, Kazis LE: Comorbidity assessments based on patient report. Results from the Veterans Health Study. Jounral of Ambulatory Care Management 2004, 27:28I-295.

21. Anderson GF: Partnership for solutions: Better Lives for People with Chronic Conditions. 2000. Robert Wood Johnson Foundation and Johns Hopkins University.; 2000.

22. Verbrugge LM, Lepkowski JM, Imanaka Y: Comorbidity and its impact on disability. The Milbank Quarterly 1989, 67:450-484.

23. Fried LP, Bandeen-Roche K, Kasper JD, Guralnik JM: Association of comorbidity with disability in older women: The Women's Health and Aging Study. Journal of Clinical Epidemiology 1999, 52:27-37.

24. Parkerson GRJ, Broadhead WE, Tse C: The Duke Severity of IIIness Checklist (DUSOI) for measurement of severity and comorbidity. I Clin Epidemiol 1993, 46:379-393.

25. Charlson M, Szatrowski TP, Peterson J, Gold J: Validation of a combined comorbidity index. J Clin Epidemiol | 994, 47: I 245- | 25 I.

26. Ware JE, Bayliss MS, Rogers WH, Kosinski M, Tarlov AR: Differences in 4-year health outcomes for elderly and poor, chronically ill patients treated in $\mathrm{HMO}$ and fee-for-service systems. Results from the Medical Outcomes Study. JAMA 1996, 276: 1039-1047.

27. National Center for Chronic Disease Prevention and Health Promotion: Behavior Risk Factor Surveillance System. 2005 [http:// apps.nccd.cdc.gov/BRFSSQuest].

28. Arroll B, Khin N, Kerse N: Screening for depression in primary care withtwo verbally asked questions: cross sectional study. BMJ 2003, 327: I I44-1।46.

29. Bosscher RJ, Smit JH: Confirmatory factor analysis of the General Self-Efficacy Scale. Behaviour Research and Therapy 1998, 36:339-343.

30. Robinson JR, Young TK, Roos LL, Gelskey DE: Estimating the burden of disease. Comparing administrative data and selfreports. Med Care 1997, 35:932-947.
31. Soumerai SB, McLaughlin TJ, Ross-Degnan D, Casteris CS, Bollini P: Effects of a limit on Medicaid drug-reimbursement benefits on the use of psychotropic agents and acute mental health services by patients with schizophrenia. The New England Journal of Medicine 1994, 33 I:650-655.

32. Sloan KL, Sales AE, Liu CF, Fishman P, Nichol P, Suzuki NT, Sharp ND: Construction and characteristics of the RxRisk-V: a VAadapted pharmacy-based case-mix instrument. Med Care 2003, 4I:76I-764.

33. Braitman LE, Davidoff $\mathrm{F}$ : Predicting clinical states in individual patients. Annals of Internal Medicine 1996, 125:406-4I2.

34. Martin LM, Leff M, Calonge N, Garrett C, Nelson DE: Validation of self-reported chronic conditions and health services in a managed care population. American Journal of Preventive Medicine 2000, 18:215-218.

35. Rector TS, Wickstrom SL, Shah M, Greenlee NT, Rheault P, Rogowski J, Freedman V, Adams J, Escarce J]: Specificity and sensitivity of claims-based algorithms for identifying members of Medicare+Choice health plans that have chronic medical conditions. Health Serv Res 2004, 39:1839-I857.

36. Mandelblatt JS, Bierman AS, Gold K, Zhang $\mathrm{Y}, \mathrm{Ng} \mathrm{JH}$, Maserjan $\mathrm{N}$, Hwang Y, Meropol NJ, Hadley J, Silliman RA: Constructs of burden of illness in older patients with breast cancer: A comparison of measurement methods. Health Serv Res 200I, 36: I085-I I 07.

37. Murray CJL, Chen LC: Understanding morbidity change. Population and Development Review 1992, I 8:48I-595.

38. Kieszak SM, Flanders WD, Kosinski AS, Shipp CC, Karp H: A comparison of the Charlson Comorbidity Index derived from medical record dat and administrative billing data. J Clin Epidemiol 1999, 52:137-142.

39. Melfi C, Holleman E, Arthur D, Datz B: Selecting a patient characteristics index for the prediction of medical outcomes using administrative claims data. J Clin Epidemiol 1994, 48:917-926.

40. Schneeweiss S, Maclure M: Use of comorbidity socres for control of confounding in studies using administrative databases. Int J Epidemiol 2000, 29:891-898.

4I. Malenka DJ, McLerran D, Roos N, Fisher ES, Wennberg JE: Using administrative data to describe casemix:a cmoparison with the medical record. J Clin Epidemiol 1994, 47: 1027-1032.

42. Wilson IB, Cleary PD: Linking clinical variables with healthrelated quality of life: A conceptual model of patient outcomes. JAMA 1995, 273:59-65.

43. Kaplan SH, Kravitz RL, Greenfield S: A critique of current uses of health status for the assessment of treatment effectiveness and quality of care. Med Care 2000, 38:II-I84-II-I9I.

44. Noel PH, Williams JW, Unutzer J, Worchel J, Lee S, Cornell J, Katon W, Harpole LH, Hunkeler E: Depression and comorbid illness in elderly primary care patients: Impact on multiple domains of health status and well-being. Annals of Family Medicine 2004, 2:555-562.

45. Ruo B, Rumsfeld JS, Hlatky MA, Liu H, Browner WS, Whooley MA: Depressive symptoms and health-related quality of life. JAMA 2003, 290:215-221.

Publish with Bio Med Central and every scientist can read your work free of charge

"BioMed Central will be the most significant development for disseminating the results of biomedical research in our lifetime. "

Sir Paul Nurse, Cancer Research UK

Your research papers will be:

- available free of charge to the entire biomedical community

- peer reviewed and published immediately upon acceptance

- cited in PubMed and archived on PubMed Central

- yours - you keep the copyright 